\title{
Livedo Reticularis
}

National Cancer Institute

\section{Source}

National Cancer Institute. Livedo Reticularis. NCI Thesaurus. Code C74524.

A recurrent purple discoloration of the skin that does not blanche and is found in a lacy, network pattern, most often in the lower extremities. It may be aggravated by exposure to cold and is classified as idiopathic or secondary. Secondary livedo reticularis may be a cutaneous manifestation of immune system disorders (e.g., lupus erythematosus, rheumatoid arthritis, cryog lobulinemia, lymphoma, etc), and hematologic disorders (polycythemia vera). 